\title{
HOW BLENDED LEARNING CAN SUPPORT A FACULTY DEVELOPMENT COMMUNITY OF INQUIRY
}

\author{
Norman Vaughan \\ University of Calgary \\ D. Randy Garrison \\ University of Calgary
}

\begin{abstract}
This study focuses on understanding the social and teaching presence required to create a blended faculty development community of inquiry. Garrison, Anderson and Archer's [1] community of inquiry framework was used to analyze transcripts from the face-to-face and online sessions of a faculty learning community focused on blended learning course redesign. All three categories of social and teaching presence were detected in both forms of transcripts. The pattern of social comments changed considerably over time within the online discussion forum. The frequency of comments reflecting affective and open communication decreased while those with group cohesion increased dramatically. A similar trend was not observed within the face-to-face transcripts. In terms of teaching presence, the percentage of comments coded for design \& organization and facilitating discourse decreased over time in both the face-to-face and online transcripts while comments containing an element of direct instruction increased considerably.
\end{abstract}

\section{KEYWORDS}

Faculty Learning Community, Community of Inquiry, Blended Learning, Transcript Analysis

\section{INTRODUCTION}

A recent survey of e-learning activity found that $80 \%$ of all higher education institutions and $93 \%$ of doctoral institutions offer hybrid or blended learning courses [2]. Moreover, most institutions of higher education are being challenged with regard to the quality of the undergraduate learning experience and, as a result, are actively redesigning their courses and programs that inevitably involve communication and Internet technologies [3]. When combined with projected faculty turn-over rates, these developments create serious professional development challenges for higher education institutions.

While the infusion of new faculty and the adoption of new communication and Internet technologies will most certainly have a positive influence in the long-term, these institutions must concurrently facilitate the integration of new faculty into a complex set of roles and responsibilities. In essence, new faculty, who are themselves in transition, are being asked to integrate into an institution in transition. This is of particular concern in terms of teaching development and preparing faculty to provide quality learning experiences. The greater proportion of new faculty in higher learning institutions have had little formal teaching development or experience. Add to this, the pressure that is being placed on these institutions to increase access to higher education, to improve the quality of student learning, and to control or reduce the rising cost of instruction, it is not difficult to see the challenge and importance of faculty support 
programs [4].

In response to these trends, many institutions have initiated faculty development programs to help the increasing number of new faculty prepare for their teaching responsibilities and effectively integrate technology into their teaching practices. These programs usually involve technology training workshops, seminars, summer institutes or project-based work with a production team to create a course web site [5]. One of the criticisms of these types of faculty development initiatives is that they do not create opportunities for sustained critical reflection and discourse about one's teaching practice. A study by Rice, Sorcinelli and Austin [6] suggests that:

New faculty want to pursue their work in communities where collaboration is respected and encouraged, where friendships develop between colleagues within and across departments, and where there is time and opportunity for interaction and talk about ideas, one's work, and the institution. (p.13)

Many have written about faculty development communities [7, 8, 9] but very little research has been conducted into how these communities function or how they affect the teaching development of the faculty involved. Faculty in higher learning institutions have indicated that they want to pursue their work in communities where collaboration is encouraged and respected, yet scheduling regular face-to-face meetings is becoming ever more difficult. Increased teaching, research and service commitments leave faculty with little time for professional development.

This research examines how a blended learning approach (face-to-face and online) supports faculty development. The question is, what role can blended learning play in creating flexible and effective communities of inquiry for faculty development? More specifically, what role can a blended community of inquiry play in supporting sustained reflection and discourse about one's teaching practice and blended learning redesign itself?

\section{THEORETICAL PERSPECTIVE}

In this study, we use the term faculty learning communities (FLCs) to describe a community of inquiry within a higher education professional development context. Cox [8] indicates that a FLC consists of "a cross-disciplinary group of five or more faculty members (8 to 12 is the recommended size) engaging in an active, collaborative, year long program with a curriculum about enhancing teaching and learning and with frequent seminars and activities that provide learning, development, interdisciplinarity, the scholarship of teaching and learning, and community building” (p.1).

At many institutions the reexamination of approaches to teaching and learning has been supported through the creation of faculty development programs. Many of these programs consist of skill-based workshops, which attempt to train faculty on how to utilize a specific technique or software application. The difficulty is that faculty often come to these workshops and became enthused about the possibilities of using educational technology but then return to their offices without the necessary time or follow-up support required to put their new ideas into practice. There is also a lack of opportunity for teachers to share their ideas, concerns, and frustrations with other faculty who are concurrently going through the same development process. In addition, those faculty members who do master these new skills often use educational technology to reinforce rather than change existing teaching practices.

Another form of faculty development involves professional development institutes [10]. These institutes usually range in length from a single day to a week long event. There is often a project focus within these 
institutes with a mix of discussion and hands-on sessions. The advantage of such institutes is that there is time to clearly link theory to practice and to also create a sense of community and interaction among the participants. The downside is the lack of follow-up after such institutes, which often prevents the implementation of new teaching techniques and strategies. Recently, a greater emphasis has been placed on faculty development initiatives, which strengthen relationships among colleagues and support stated institutional goals [11]. Research by Lieberman [12] also suggests that a collegial network is fundamental to effective professional development in education.

Slavit, Sawyer and Curley [13] state that "It is becoming very clear that professional development must be an ongoing activity, as 'shotgun' approaches often do little to promote real change” (p.35). Thus, these types of programs should occur over an extended period, such as a semester or academic year, to allow participants time to transform their teaching practice. One example of a faculty development program, which typifies this new focus on community and a connection to an institutional mandate, is the Faculty Learning Community (FLC) initiative at Miami University [8]. The faculty participants in a FLC engage in a continuous process of reflection and discourse about complex teaching problems. There is constant support from colleagues throughout this process but there is a focus on "getting things done" [7, p.2]. Survey data from the Cox study indicate that as a result of the FLC process, faculty have increased their interest in the teaching process (86\%) and their view of teaching as an intellectual pursuit (82\%).

Another community based faculty development effort is the Visible Knowledge Project (VKP) that focuses on innovation and deep learning experiences using technology through a systematic inquiry of faculty teaching practice [14]. Wenger's [15] community of practice framework has been used to guide the VKP study.

A third faculty development exemplar is that of the University of Central Florida [16]. This development program employs a blended model of delivery. The purpose of the program is to help faculty succeed at planning, designing and developing their own technology-mediated courses (completely online or blended learning format). This program has been shown to be highly successful from an instructor and student perspective. A survey of UCF faculty found that $87 \%$ indicated that they changed their approach to teaching as a result of their experience teaching a technology-mediated course. Moreover, student survey results indicate that on average, mixed mode (blended) courses have higher success rates (percentage of students obtaining an A, B, or C) and lower withdrawal rates than comparable face-to-face courses [17].

At the University of Wisconsin in Milwaukee, a faculty development program is modeled after the University of Central Florida but with a specific focus on hybrid (blended) learning. This program attempts to model effective blended course practices and provide faculty with a hands-on blended learning experience through a series of face-to-face, online, and independent activities. The hybrid/blended faculty development program takes place over a six month time period and consists of six modules [18]. Three of these modules are completed in day-long, face-to-face sessions and the other three online. Participants involved in this faculty development initiative have been very positive about the program and their teaching experiences.

While there is growing evidence about the importance of creating community for faculty development in higher education if long-term changes are to be realized, there is currently an absence of models to guide the development of such initiatives. The two concepts that frame our approach to faculty learning communities are communities of inquiry and blended learning. 


\section{A. Community of Inquiry}

There is an extensive body of literature about community in educational contexts. This study will focus specifically on communities of inquiry as described by Garrison et al. [1]. The community of inquiry (CoI) model was developed to explore how online communication and discourse can facilitate higherorder thinking skills. This framework consists of three core elements: social, teaching and cognitive presence. The sphere of social presence refers to the "ability of participants in a community of inquiry to project themselves socially and emotionally as 'real' people (i.e., their full personality), through the medium of communication being used" [1, p. 94]. The element of teaching presence includes the "design, facilitation, and direction of cognitive and social processes for the purpose of realizing personally meaningful and educationally worthwhile learning outcomes" [19, p.1]. Cognitive presence is "the extent to which learners are able to construct and confirm meaning through sustained reflection and discourse in a critical community of inquiry” [20, p.11]. Descriptors and indicators of each of the three elements are presented in Table 1.

Table 1: Community of Inquiry Categories

\begin{tabular}{|l|l|l|}
\hline \multicolumn{1}{|c|}{ Elements } & \multicolumn{1}{|c|}{ Categories } & \multicolumn{1}{c|}{ Indicators (examples only) } \\
\hline Social Presence & $\begin{array}{l}\text { Affective expression } \\
\text { Open communication } \\
\text { Group cohesion }\end{array}$ & $\begin{array}{l}\text { Emoticons } \\
\text { Express trust, agreement } \\
\text { Encourage collaboration }\end{array}$ \\
\hline Teaching Presence & $\begin{array}{l}\text { Design \& organization } \\
\text { Facilitating discourse } \\
\text { Direct instruction }\end{array}$ & $\begin{array}{l}\text { Defining content \& activities } \\
\text { Sharing meaning } \\
\text { Focusing discussion }\end{array}$ \\
\hline Cognitive Presence & Triggering event & Sense of puzzlement \\
& Exploration & Information exchange \\
& Integration & Connecting ideas \\
& Apply new ideas
\end{tabular}

\section{B. Blended learning}

The concept of blending different learning experiences has been in existence ever since humans started thinking about teaching [21]. What has recently brought this term into the limelight is the infusion of Web-based technologies into the learning and teaching process [22]. These technologies have created new opportunities for students to interact with their peers, faculty and content; inside and outside of the classroom.

The term blended learning is used in this research study to refer to the "thoughtful integration of classroom face-to-face learning experiences with online learning experiences ... such that we are not just adding on to the existing dominant approach or method" [23, pp. 96-97]. A significant portion of the learning activities have been moved online, and time traditionally spent in the classroom is reduced but not eliminated. Blended learning represents a fundamental reconceptualization and redesign of the educational experience. The goal of this blended learning approach, in higher education, is to join the best features of in-class teaching with the best features of online facilitation to promote active and self directed learning opportunities for students [18].

Currently, there is an absence of research literature about how blended learning can be successfully applied to a faculty development context. Aycock, Garnham and Kaleta [24] propose that such a learning 
How Blended Learning Can Support a Faculty Development Community of Inquiry

design could be used to facilitate inquiry into one's teaching practice, potentially resulting in improved student learning outcomes. In order to achieve this benefit, it is suggested that the faculty development program should provide the time, support and encouragement for participants to reexamine and reflect on their course curriculum, teaching practice, and use of educational technology [24]. Sands [25] indicates that technology should be used as a catalyst to question one's curriculum and pedagogy. Garnham and Kaleta [18] state that "The process of answering this question-' what will I teach online and what will I teach face-to-face?'-provides critical information about the discipline, content, teaching methods, learning processes, and the media and technologies available to support the most effective combination" (p. 3).

Voos [26] echoes these comments by emphasizing that "when faculty redesign material they know deeply for a new delivery modality, breakthroughs are made in student learning, student satisfaction and faculty satisfaction” (p. 4). A blended learning design supports this type of inquiry by creating opportunities for sustained reflection and critical discourse. On-going face-to-face sessions allow personal relationships and a sense of community to develop, which fosters the sharing of ideas and experiences amongst the participants. And, the online component of the blended design creates an opportunity to extend and sustain this type of discourse and community. In addition, the reflective nature of asynchronous online communication has been well documented [27, 28]. As a result of these complementary benefits, interest is beginning to grow about how blended learning can be applied within a faculty development context.

\section{METHODOLOGY}

This research study examined a faculty learning community (FLC) at a Canadian community college during 2003. This FLC program was piloted during the Winter 2003 semester. The feedback from the pilot study informed the design and organization of the primary study. (For a description of the pilot and learning activities see [29]).

The study's primary FLC met during the Fall 2003 term. The goal of the FLC was the successful blended learning redesign of undergraduate credit courses. All college faculty members (part and full time) were eligible to formally apply to the college's senior administration to become members of the FLC. Based on criteria related to innovation, collaboration and experience with technology, 12 faculty members were chosen from 25 applications. The faculty members were from a wide range of disciplines. The first author of this study was the coordinator and leader of the FLC.

Data were collected from the transcripts of the face-to-face and online discussion forums. The transcripts from the first and last (sixth) bi-weekly discussions were analyzed by two trained graduate students. Transcript analysis was used to identify categories of social, teaching and cognitive presence for both face-to-face and online transcripts. The intent of this procedure was to also identify the key differences and/or similarities in the three presences between the face-to-face and online transcripts.

The unit of analysis for this study was a single message for the computer-mediated discussion forum transcripts and a single participant response for the oral transcripts. Inter-rater reliability was determined using Holsti's [30] coefficient of reliability (CR) and Cohen's [31] kappa (k) formula for the chance corrected measure. The coding protocol is described fully in Vaughan [29].

Data were also collected from post-study interviews, which were conducted individually with each FLC participant. In this regard, key themes were identified from the participants' responses and then the community of inquiry framework was used as a tool to categorize these themes. 


\section{FINDINGS}

The research reported here focuses on understanding the presences required to create a blended faculty development community of inquiry. Data analysis from the transcripts and interviews follow.

\section{A. Transcript Analysis}

Transcripts from both the face-to-face and online sessions were analyzed from the perspective of social, teaching, and cognitive presence. For social presence (Table 2), the number of postings coded for online affective communication and open communication decreased between the first and sixth bi-weekly discussions. At the same time, those coded for group cohesion increased dramatically (3\%-71\%). The coders indicated that several postings in these online discussions did not contain any element of social presence. In comparison, for the face-to-face discussions, there were no clearly identifiable trends between the first and sixth bi-weekly discussion sessions and there was a somewhat even distribution among the three categories of social presence. The number of comments in which the two coders could not detect any social presence within the face-to-face transcripts almost doubled between the first and sixth bi-weekly sessions, which along with the small sample size may account for why the chance corrected measure of inter-rater reliability $(\mathrm{k})$ decreases substantially between these two sessions (.86 to $.46)$.

Table 2: Social Presence - Comparison of Online and Face-to-Face Transcripts

\begin{tabular}{|c|c|c|c|c|c|c|c|c|}
\hline & \multicolumn{4}{|c|}{ Online Transcripts } & \multicolumn{4}{|c|}{ Face-to-Face Transcripts } \\
\hline & \multicolumn{2}{|c|}{$1^{\text {st }}$ Discussion } & \multicolumn{2}{|c|}{$6^{\text {th }}$ Discussion } & \multicolumn{2}{|c|}{$1^{\text {st }}$ Discussion } & \multicolumn{2}{|c|}{$6^{\text {th }}$ Discussion } \\
\hline Category & Totals & $\%$ & Totals & $\%$ & Totals & $\%$ & Totals & $\%$ \\
\hline Affective & 17 & $53 \%$ & 4 & $19 \%$ & 80 & $33 \%$ & 57 & $26 \%$ \\
\hline $\begin{array}{c}\text { Open } \\
\text { Communication }\end{array}$ & 11 & $35 \%$ & 1 & $5 \%$ & 77 & $32 \%$ & 61 & $28 \%$ \\
\hline Group Cohesion & 1 & $3 \%$ & 15 & $71 \%$ & 48 & $20 \%$ & 38 & $17 \%$ \\
\hline $\begin{array}{l}\text { No category } \\
\text { detected }\end{array}$ & 3 & $9 \%$ & 1 & $5 \%$ & 35 & $15 \%$ & 64 & $29 \%$ \\
\hline Totals & 32 & $100 \%$ & 21 & $100 \%$ & 240 & $100 \%$ & 220 & $100 \%$ \\
\hline CR & & & & & & & & \\
\hline $\mathbf{k}$ & & & & & & & & \\
\hline
\end{tabular}

For teaching presence (Table 3), the number of postings coded for online design and organization remained virtually the same between the first and sixth bi-weekly discussions (3\%-5\%). The responses coded for facilitating discourse decreased (84\%-52\%), while the number of direct instruction postings increased (13\%-43\%). The two coders indicated that all the postings in both the first and sixth bi-weekly online discussion sessions contained an element of teaching presence. The extensive nature of this presence in the online transcripts coupled with the on-going practice of the coders and small sample size may explain the high degree of inter-rater reliability (1.00) for the sixth session. 
With regards to the face-to-face discussions, as might be expected, there were a greater number of design and organization comments coded for the first discussion session but decreased for the sixth bi-weekly discussion session (21\%-2\%). The trends for the facilitating discourse and direct instruction postings were similar to the online discussions. There was a decrease in the number of comments coded for facilitating discourse (43\%-26\%) and an increase in the number coded for direct instruction (8\%-40\%). The two coders specified that they could not detect any form of teaching presence in almost one-third of the comments within both face-to-face transcripts.

Table 3: Teaching Presence - Comparison of Online and Face-to-Face Transcripts

\begin{tabular}{|c|c|c|c|c|c|c|c|c|}
\hline & \multicolumn{4}{|c|}{ Online Transcripts } & \multicolumn{4}{|c|}{ Face-to-face Transcripts } \\
\hline & \multicolumn{2}{|c|}{$1^{\text {st }}$ Discussion } & \multicolumn{2}{|c|}{$6^{\text {th }}$ Discussion } & \multicolumn{2}{|c|}{$1^{\text {st }}$ Discussion } & \multicolumn{2}{|c|}{$6^{\text {th }}$ Discussion } \\
\hline Category & Totals & $\%$ & Totals & $\%$ & $\begin{array}{c}\text { Total } \\
\mathrm{s}\end{array}$ & $\%$ & Totals & $\%$ \\
\hline $\begin{array}{c}\text { Design \& } \\
\text { Organization }\end{array}$ & 1 & $3 \%$ & 1 & $5 \%$ & 51 & $21 \%$ & 5 & $2 \%$ \\
\hline $\begin{array}{l}\text { Facilitating } \\
\text { Discourse }\end{array}$ & 27 & $84 \%$ & 11 & $52 \%$ & 102 & $43 \%$ & 57 & $26 \%$ \\
\hline Direct Instruction & 4 & $13 \%$ & 9 & $43 \%$ & 20 & $8 \%$ & 88 & $40 \%$ \\
\hline $\begin{array}{c}\text { No teaching } \\
\text { presence detected }\end{array}$ & 0 & $0 \%$ & 0 & $0 \%$ & 67 & $28 \%$ & 70 & $32 \%$ \\
\hline Totals & 32 & $100 \%$ & 21 & $100 \%$ & 240 & $100 \%$ & 220 & $100 \%$ \\
\hline $\mathbf{C R}$ & & & & & & 8 & & \\
\hline $\mathbf{k}$ & & & & & & 6 & & \\
\hline
\end{tabular}

The researchers were particularly interested in comparing the nature of cognitive presence between the online and face-to-face discussions and thus all six sessions, for both modes of dialogue, were analyzed. A comparison of the compiled results for cognitive presence (i.e., inquiry process) indicates that, on average, there were fewer triggering events coded in the online discussions than in the face-to-face ones (Table 4). In both forms of discussion, almost two-thirds of the messages were coded for exploration. There was a higher percentage of integration detected in the online sessions and virtually no resolution/application phase identified in either the online or face-to-face transcripts. The two coders could not detect any phase of cognitive presence in 14 percent of the online discussion postings nor in $25 \%$ of the face-to-face comments.

Table 4: Cognitive Presence - Comparison of Online and Face-to-Face Transcripts

\begin{tabular}{|c|c|c|c|c|}
\hline & \multicolumn{2}{|c|}{$\begin{array}{c}\text { Compiled Results for } \\
\text { Online Transcripts }\end{array}$} & \multicolumn{2}{c|}{$\begin{array}{c}\text { Compiled Results for } \\
\text { Face-to-Face } \\
\text { Transcripts }\end{array}$} \\
\hline Phase & Totals & Percentages & Totals & Percentages \\
\hline Triggering Event & 14 & $8 \%$ & 268 & $13 \%$ \\
\hline Exploration & 109 & $61 \%$ & 1211 & $60 \%$ \\
\hline Integration & 29 & $16 \%$ & 29 & $2 \%$ \\
\hline
\end{tabular}




\begin{tabular}{|c|c|c|c|c|}
\hline Resolution/Application & 2 & $1 \%$ & 0 & $0 \%$ \\
\hline No phase detected & 25 & $14 \%$ & 501 & $25 \%$ \\
\hline Total & 179 & $100 \%$ & 2009 & $100 \%$ \\
\hline CR & \multicolumn{2}{|c|}{.86} & \multicolumn{2}{c|}{.92} \\
\hline $\mathbf{r}$ & .84 & \\
\hline
\end{tabular}

\section{B. Interview Analysis}

Post study interviews were conducted for all the study participants in the FLC. Each interview was transcribed and analyzed. As gleaned from the interview responses, the key questions for faculty were related to technology, design issues, time available for redesign, workload in delivering the blended course, and ability to maintain the course. Faculty also indicated they were initially concerned about student and colleague resistance to the delivery changes and the use of online learning technology occurring within a blended course.

One of the interview questions asked the faculty members to describe how the FLC had helped them resolve their initial questions and concerns about blended learning and the integration of educational technology into their teaching practice. The compiled interview themes and corresponding quotations revealed that all three presences of the community of inquiry model played an important role in helping the faculty participants resolve their initial questions and concerns [29].

For social presence, participants indicated that the FLC provided them with the support of belonging to a group (community), the opportunity for peer feedback, and the motivation to complete their blended learning project. This is reflected in the comment "small face-to-face and online discussions sessions quickly allowed a sense of intimacy to develop. The sense of openness and trust that was created in these sessions allowed me to freely share my fears and concerns around the use of educational technology to support a blended learning environment for my own students.”

The teaching presence aspects of the FLC, which the participants identified as being important for helping the faculty resolve their initial questions and concerns about blended learning and educational technology integration included: the structured face-to-face and online sessions, the small group workshop format, the relevance of session topics, and the collegial support for project development. The value of the blended learning environment was highlighted by the comment "The face-to-face sessions allowed me to learn from others directly and the online sessions allowed me to reflect and share my ideas about blended learning with the other members of the group."

In terms of cognitive presence or inquiry, the participants stated that the FLC experience helped them to understand the rationale for blended learning, exposed them to new ideas, which triggered new practical inquiry cycles, and provided opportunities to share ideas and resources with others. A senior member of the group remarked that "This program provided me with the opportunity and time to reflect on my own teaching practice and to also engage in a collaborative dialogue with others about my practice and theirs."

The study participants were asked in the individual interviews to identify the differences and/or similarities between the face-to-face and online discussions. This multi-part question asked participants to comment on how online and face-to-face components contributed to their further understanding about 
blended learning, whether the two components complemented each other, and what were the similarities and/or differences between the two components?

The participants stressed the importance of establishing and maintaining a social presence in order to sustain an inquiry process within a faculty learning community. They stated that the face-to-face sessions allowed them to engage in a familiar and immediate form of communication, which helped create a sense of human connection (social presence) between the members of the FLC. As one faculty participant indicated, the face-to-face sessions "had a warm, fuzzy feeling to them because we were a small group" and that this "(c)reated a safe environment where people feel willing to speak their mind and freely talk about what they are thinking.” It was also evident that the online component was essential for "sustaining the momentum" and maintaining the sense of community between the face-to-face sessions. This sentiment was captured in an interview comment, which indicated that the computer mediated discussions allowed participants to "do some research and reflection and then post this information to the group immediately rather than waiting two weeks for our next face-to-face meeting-you are really keeping the momentum and energy of the discussion and the ideas moving forward rather than stagnating movement between sessions.”

In terms of teaching presence and design, the participants indicated that the regular bi-weekly face-to-face sessions with a clear agenda and structure helped create a regular rhythm for the community. In this regard, one participant stated "(k)nowing that we were meeting every two weeks and that we were responsible for discussing issues each week online kept this project in my thoughts throughout the semester. Otherwise it would probably have been shoved to the back burner". Other FLC members also suggested that the blending of the face-to-face and online sessions allowed for the creation of public and private space to communicate within the FLC.

The faculty involved in this study also highlighted how the blending of the face-to-face and online components helped to facilitate on-going discourse within the community. The small group workshop format of the face-to-face sessions, combined with the asynchronous online discussion forums, enabled all community members to share their perspectives and to participate in the on-going discussions at different levels, time periods and access points. The sustained nature of the discussions is illustrated in the following interview comment:

Probably the most beneficial aspect of the FLC was the on-going sharing with other faculty members. I appreciated hearing the experiences and approaches of others considering the wide variety of courses and personalities within our group. Overall, the sharing of perspectives throughout the semester opened up my thinking on how to approach my own blended learning course.

In terms of the third teaching presence category, direct instruction, one participant stated that it takes a "strong hand on the wheel” to ensure that discussions within a FLC stay "on task and on track."

\section{DISCUSSION}

All three categories of social presence were detected in both the face-to-face and online discussion transcripts. Moreover, it was noted that the pattern of social comments changed considerably over time within the online discussion forum. The frequency of comments reflecting affective and open communication decreased while those with group cohesion increased dramatically. These trends suggest that patterns of affective and open communication within the online environment need to be established among members of a FLC before group cohesion can take place. Interestingly, however, a similar trend 
was not observed within the face-to-face transcripts for the distribution of the three categories of social presence. The coding pattern indicated a much more even division of comments in the face-to-face sessions.

One explanation offered is that there is evidence that the online group began to shift their cognitive presence from exploration to integration. It has been theorized that the strength of online discussion is in support of creating cognitive presence. It is hypothesized that this is partly due to the asynchronous nature of the communication where there is less need to attend to interpersonal sensitivities [27]. That is not to say social presence was not present, but that it was less frequent. As we see in the next paragraph, it would appear that online social presence is less spontaneous and more deliberate. Equally importantly, group cohesion had been established through early face-to-face sessions. Thus, there would appear not to be as great a need to attend to affective and open communication issues by the time the sixth bi-weekly discussion session was reached.

It is also interesting to note that in a post-study interview with the two research assistants who coded the transcripts, they noticed different patterns of social presence between the two forms of discussion. In support of the previous analysis the coders detected a more structured and deliberate pattern of social presence within a message for the online discussion. The two coders indicated that there was a chaotic pattern of social presence within the face-to-face comments as these messages were often incomplete, as they had been truncated by the sudden interruption or injection of comments from other participants. With regard to the specific categories of social presence, the coders did not comment on any differences for affective communication between the face-to-face and online transcripts. However, they did detect differences for the other two categories. For open communication, the research assistants indicated that expressions of appreciation or praise for another participant's comment appeared to be more intentional within the online discussions, whereas within the face-to-face transcripts these complimentary remarks seemed to be made in a less conscious and more spontaneous manner demonstrated in comments such as, "Yeah, that's a good idea, wow."

For the group cohesion category, the coders stated that the use of inclusive pronouns such as; "we”, "us" and "our", were commonly observed in the face-to-face transcripts but very rarely seen in the online discussion transcripts. This difference may be attributed to the physical presence within the face-to-face sessions. The participants were able to see each other within these discussions and identified themselves as a group rather than just a collection of individuals. Within the online discussions, the participants were alone when they were typing their messages and thus may have thought of themselves more on the individual level, even though they were writing to the group. This is substantiated in the following participant comment “in the face-to-face sessions you could use body language and read other people's physical expressions to communicate while in the online sessions I was much more focused and reflective in my communication because I was alone.”

In the interviews, the participants clearly stated the importance of the face-to-face sessions for establishing social presence within the FLC. They stated that the face-to-face sessions allowed them to engage in a familiar and immediate form of communication, which helped create a sense of human connection (social presence) between the members of the FLC. In this regard, Wenger, McDermott and Snyder [32] suggest that the "essence" of a community can decay over time if a regular physical presence is not maintained. At the same time, it was apparent that the growth and development of a community can be enhanced through online communication. Evidence here suggests that blending face-to-face and online interaction would appear to greatly enhance social presence. The participants indicated that the regular face-to-face sessions with a clear agenda and structure helped create a regular rhythm for the community. 
The full integration of face-to-face and online approaches for the creation of social presence and sustaining community does not happen by chance but through the intentional application of teaching presence. In terms of the design and organization category, the faculty participants commented that the structure and format of the face-to-face and online sessions contributed to their learning success with the FLC. Students in a related study by Rourke and Anderson [33] also identified structure as a key characteristic of a good discussion. Despite the importance that participants placed on the design and organization of the learning experience, this category of teaching presence was observed in very few discussion messages (see Table 3). Anderson et al. [19] suggest the reason this form of teaching presence is not more visible within discussion forum transcripts is that the design and organization of a program begins well before the first session of a FLC or course. However, there were a significant number of design and organization comments within the first FLC face-to-face discussion but this category of teaching presence diminished over time. Within the individual interviews, several of the participants stated that the initial face-to-face session enabled them to gain a better understanding of the program goals of the FLC, which meant that there was less need to seek further clarification about the program within the online discussion forums or the subsequent face-to-face sessions.

The second category, facilitating discourse was critical for maintaining the interest, motivation and engagement of the participants within the FLC. The findings from this study indicate that facilitating discourse was very important in the initial stages of the FLC for encouraging faculty members to participate in the face-to-face sessions and especially the online discussion forums, which were a new form of communication for many of the participants. Similar to the social presence category of affective communication, the need for facilitating discourse diminished over time, as the FLC members became more comfortable communicating with each other. The participants highlighted how the blending of the face-to-face and online components helped to facilitate on-going discourse within the communities. The face-to-face sessions combined with the asynchronous online discussion forums enabled all community members to share their different perspectives about blended learning and to participate in the on-going discussions at different levels, time periods and access points.

Here again, the research assistants who coded the transcripts provide important insights. They observed that for teaching presence, the majority of the coordinator's messages contained the category of facilitating discourse. They also indicated that these messages were more structured and intentional than those of the participants as they provided deliberate support comments and focused examples of personal experience.

The third category of teaching presence is direct instruction. Garrison and Anderson [27] indicate that direct instruction goes beyond facilitation and is most often associated with specific content issues, such as diagnosing misconceptions. While this element of direct instruction is initially the responsibility of the program coordinator, in order for everyone within a FLC to achieve a sense of empowerment this role should be shared over time. This is particularly important in a FLC as participants expect and need to take responsibility and control for their course redesign.

The coding trends for the category of direct instruction are very interesting as they suggest that over time, the FLC experience has empowered the participants to begin teaching each other about blended learning and educational technology integration through the establishment of open and trusting relationships. This is demonstrated by the substantial change between the first and sixth bi-weekly discussion sessions in the percentage of messages coded for direct instruction and the social presence category of group cohesion. For the initial sessions, only $8 \%$ of the face-to-face and $13 \%$ of the online messages were coded for direct instruction. These percentages increased considerably for the sixth bi-weekly session in which $40 \%$ of the face-to-face and $43 \%$ of the online messages were detected to contain evidence of direct instruction. 
The results of this study point to the importance of teaching presence in establishing a community of inquiry. Design and organization is crucial during the planning phase for a FLC in order to make certain that there is a clear purpose and structure for the face-to-face sessions and online activities. There is an initial need for the development leader and coordinator to facilitate a great deal of discourse, especially in the online component, in order to encourage all members of a FLC to participate within the discussions. Over time, this will diminish as participants become more comfortable and begin to share responsibility for direct instruction within the FLC.

\section{CONCLUSION}

Numerous higher education institutions are currently wrestling with the question of how asynchronous leaning networks can be used to support faculty development. A survey of faculty learning communities reveals that $90 \%$ of the respondents are using some form of online communication, such as e-mail or discussion groups within their faculty learning communities [34]. When combined with the results of this study, these survey findings strongly support the use of a blended faculty learning community approach that will create a flexible and accessible environment for faculty to engage in sustained critical reflection and discourse about their teaching practice. This support becomes ever more important as the need for course redesign in higher education grows.

The key to creating a cohesive, purposeful and worthwhile community of inquiry is the integration of social, teaching and cognitive presence. It has been shown here that a blended approach to a faculty learning community may provide an optimal experience between community support and addressing the practicality of time constraints. The challenge is to recognize the changing dynamics of the faculty learning communities over time and the need to adjust social, cognitive and teaching presence strategies to meet the evolving demands of inquiry for faculty development. Each of the three presences manifest themselves and evolve in different ways in a face-to-face or online context.

\section{REFERENCES}

1. Garrison, D. R., T. Anderson and W. Archer. Critical Inquiry in a Text-Based Environment: Computer Conferencing in Higher Education. The Internet and Higher Education 2(2-3): 87-105, 2000.

2. Arabasz, P. and M. B. Baker. Evolving campus support models for e-learning courses. Educause Center for Applied Research Bulletin, 2003. http://www.educause.edu/ir/library/pdf/ecar_so/ers /ERS0303/EKF0303.pdf.

3. Twigg, C. A. Improving Learning and Reducing Costs: New Models for Online Learning. Educause Review 38(5): 29-38, 2003.

4. Kenny, R. W. Reinventing Undergraduate Education: A Blueprint for America's Research Universities. Stony Brook, NY: University of New York at Stony Brook, 1998. http://naples.cC .sunysb.edu/Pres/boyer.nsf/.

5. Murray, J. P. Faculty Development in SACS-Accredited Community Colleges. Community College Review 29(4): 50-66, 2002.

6. Rice, R., M. Sorcinelli and A. Austin. Heeding New Voices: Academic Careers for a New Generation. Working Paper Inquiry \#7. Washington, DC: American Association for Higher Education, 2000.

7. Cox, M. D. Introduction to Faculty Learning Communities. In Cox, M.D and Richlin, L. (Eds.), Building Faculty Learning Communities: New Directions for Teaching and Learning 97: 5-23. Jossey-Bass: San Francisco, CA, 2004. 
8. Cox, M. D. Achieving Teaching and Learning Excellence through Faculty Learning Communities. Essays on Teaching Excellence: Toward the Best in the Academy 14(4): 2002.

9. Layne, J., J. Froyd, J. Morgan and A. Kenimer. Faculty Learning Communities. ASEE/IEEE Conference Proceedings, 2002.

10. Cagle, A. B. and S. Hornik. Faculty development and educational technology. T.H.E. Journal 29(3): 92-6, 2001.

11. Camblin, L. D. Jr. and J. A. Steger. Rethinking faculty development. Higher Education (39): 1-18, 2000.

12. Lieberman, A. Practices That Support Teacher Development. Phi Delta Kappan 76(8): 591-596, 1995.

13. Slavit, D., R. Sawyer and J. Curley. Filling Your PLATE: A Professional Development Model for Teaching with Technology. TechTrends 47(4): 35-38, 2003.

14. Visible Knowledge Project and Georgetown University. Visible Knowledge Project: Learning Technology Inquiry, 2002. http://crossroads.georgetown.edu/vkp/.

15. Wenger, E. Communities of Practice: Learning, Meaning, and Identity. New York: Cambridge University Press, 1998.

16. Dziuban, C., J. Hartman, P. Moskal, S. Sorg, and B. Truman. Three ALN modalities: An institutional perspective. In J. Bourne, J. and Moore, J.C. (Eds.), Elements of Quality Online Education: Into the Mainstream, 127-148. Needham, MA: Sloan-C, 2004.

17. Dziuban, C., J. Hartman and P. Moskal. Blended Learning. Educause Center for Applied Research Bulletin, 2004. http://www.educause.edu/ir/library/pdf/ERB0407.pdf.

18. Garnham, C. and R. Kaleta. Introduction to Hybrid Courses. Teaching with Technology Today 8(6): 2002.

19. Anderson, T., L. Rourke, D. R. Garrison, and W. Archer. Assessing teaching presence in a computer conferencing environment. Journal of Asynchronous Learning Networks 5(2): 2001.

20. Garrison, D. R., T. Anderson and W. Archer. Critical thinking, cognitive presence, and computer conferencing in distance education. American Journal of Distance Education 15(1): 17-23, 2001.

21. Williams, J. Blending into the Background. E-Learning Age Magazine 1: 2003.

22. Clark, D. Blend it like Beckham. White Paper: Blended Learning, 2003. http://www.epic.co.uk /content/resources/white_papers/blended.htm.

23. Garrison, D. R. and H. Kanuka. Blended Learning: Uncovering its Transformative Potential in Higher Education. The Internet and Higher Education 7(2): 95-105, 2004.

24. Aycock, A., C. Garnham and R. Kaleta. Lessons Learned from the Hybrid Course Project. Teaching with Technology Today 8(6): 2002.

25. Sands, P. Inside Outside, Upside Downside: Strategies for Connecting Online and Face-to-face Instruction in Hybrid Courses. Teaching with Technology Today 8(6): 2002.

26. Voos, R. Blended Learning-What is it and where might it take us? Sloan-C View 2(1): 2003.

27. Garrison, D. R. and T. Anderson. E-Learning in the 21st Century: A Framework for Research and Practice. London: RoutledgeFalmer, 2003.

28. Sloffer, S. J., B. Dueber and T. M. Duffy. Using asynchronous conferencing to promote critical thinking. Two implications in higher education. CRLT Technical Report 8(99). Bloomington, IN: Center for Research on Learning and Technology, Indiana University, 1999.

29. Vaughan, N. D. Investigating How a Blended Learning Approach can Support an Inquiry Process within a Faculty Learning Community. University of Calgary. Unpublished Dissertation, 2004.

30. Holsti, O. Content analysis for the social sciences and humanities. Don Mills: Addison-Wesley Publishing Company, 1969.

31. Cohen, J. A coefficient of agreement for nominal scales. Educational and Psychological Measurement 20: 37-46, 1960.

32. Wenger, E., R. McDermott and W. M. Snyder. Cultivating Communities of Practice: A Guide to Managing Knowledge. Boston: Harvard Business School Publishing. Press, 2002. 
33. Rourke, L. and T. Anderson. Using peer teams to lead online discussion. Journal of Interactive Media in Education, 1, 2002. http://www-jime.open.ac.uk/2002/1/rourke-anderson-02-1-t.html.

34. Richlin, L and Essington, A. Overview of Faculty Learning Communities. In Cox, M.D. and Richlin, L. (Eds.), Building Faculty Learning Communities: New Directions for Teaching and Learning 97: 25-39. Jossey-Bass: San Francisco, CA, 2004.

\section{ABOUT THE AUTHORS}

Dr. Norman Vaughan is the Coordinator of the Inquiry through Blended Learning (ITBL) program within the Learning Commons at the University of Calgary. He has over two decades of combined postsecondary, adult education, K to 12 and workplace training and teaching experience. His current research interests are focused on blended learning and faculty development issues in higher education.

Dr. D. Randy Garrison is the Director of the Learning Commons at the University of Calgary. He is also a full professor in the Faculty of Education. He served as Dean, Faculty of Extension at the University of Alberta from 1996 to 2001. Randy has published extensively on teaching and learning in distance, higher, and adult education contexts. 